\section{ON THE RADICAL CURE OF HERNIA.}

Introduction to a Discussion at a Mccting of the Staffordshire Branch.

BY W. DUNNETT SPANTON, F.R.C.S.ED., M.R.C.S.Exi., Surgeon to the North Staftordshire Intirmary.

Is introducing the subject of the operative cure of hernia for discussion, in obedience to the request of our exccllent secretary, I shall, perhaps, best attain the object in view by making my remarks of a general, rather than a systematic or statistical character. If the importance of the subject may be gauged by the amount of literature and discussion expended upon it, we may fairly conclude that it has, during the last four or five ycars, taken rank among one of the prominent surgical questions of the day. For a long time, it was quite a rare event to find any reference to it, except an occasional record of a case of Wood's or Wutzer's operation; but now that is all changed ; and why?

No doubt the introduction of so-called antiseptic surgery has had much to do with this advance; but far more is it due to the removal of the long standing prejudice on the part of the teachers of surgery against operations of every description for the cure of reducible hernia. As long as surgeons carefully excluded from their lectures and their text-books any commendation of such procedures, it was hardly to be expected that practitioners generally would either advise or adopt them. The fact is that, as an operation of expediency, that for the cure of reducible hernia has long had a bad name, and has been followed by the usual consequences; and surgical authors, like so many surgical sheep, have followed each other astray, without venturing to find out for themselves the worth or the danger of any of the operations which have from time to time been advocated. For many years, the excessive mortality which followed them no doubt deterred prudent and conscientious surgeons from undertaking what they might consider an unjustifiable risk; and if we come to analyse some of these figures, there is certainly grave reason for such hesitation. In the earlier operations of Langenbeck of Borlin, and Schumacher, for ligature and excision of the sac, there are recorded three deaths in ten cases; and, taking all the cases which have been reported in the medical journals for the last few years of the various forms of open operation by ligature, I find 147 cases with eight deaths, a mortality of $5 \frac{1}{2}$ per cent.

It is necessary to draw a broad line between the reducible and the strangulated form, of whatever class it may be. Statistics have been given, and numerous instances recorded, in which a so-called radical cure has been effected conjointly with an operation for the relief of strangulation, along with other instances where an operation has been performed of a puroly expedient character for the cure of an ordinary reducible rupture.

It is, of course, quite impossible, in a case of strangulation, to say how far a fatal termination may be due to what is done at the time of operation, or how much must be attributed to preceding mischief; and all such cases should, therefore, be classed by themselves. On the other hand, in dealing with an ordinary reducible rupture in a healthy person, if anything do go wrong, we may safely assume that it is propter as well as post hoc. These cases ought, therefore, likewise, to be considered apart. Some surgeons who have published cases have mixed them up in such a manner as to deprive them of much of their value. For example, of sixteen cases described by Sir W. Mac Cormac as "operations for the radical cure of hernia," only two were simple cases; in all the others, strangulation had occurred. If this confusion be maintained, we can hardly hope that the operation will ever free itself from the stigma of being accompanied by a high rate of mortality, which such an association is almost certain to convey.

For many years it has been the usual custom, at some hospitals, to combine with the ordinary operation for strangulation that of ligature of the sac, and closure of the hernial ring. Mr. Bryant tells me that this has been practised at Guy's Hospital for many years. At the North Staffordshire Infirmary my colleagues and I have done this for a long time, and with excellent results. It would be tedious to relate cases in support of the practice, because it is, I believe, recognised. as legitimate and safe; but $I$ may say that in the last instance in which I did it, that of a femoral herniz, in an old lady, 76 years of age, under unfavourable conditions so far as concerned the strangulation, her recovery was rapid and complete, and the hernia has not troubled her since.

There are, of course, many instances met with, in which it would be quite inadmissible; such, for example, as extreme exhaustion of the jatieut, where it would be obviously wroner to add one iota to the shock already existing. Whore, again, the bowel is in a gangrenous condition, especially when adherent to tho sac, it would be more prudent not to attempt it. It is, in fact, one of those operations of which the surgeon must be the judge at the time of its performance. Only, it should be the rule rather than the exception. The opportunity afforded by a strangulated condition to effect a solid cure, should also prove an inducement to operate as early as possible in every case, without waiting to see how completely it is possible to defeat Nature's efforts by that species of taxis which results in inflammation of the bowel, or perhaps sloughing of the sac or omentum. I had an illustrative case of this kind quite recently. A man of middle age, with a history of scrotal hernia of long standing, was scizel with some of the symptoms of strangulation, but without constipation. Taxis was perseveringly employed, with the result that he was brought to the hospital witli a large suppurating scrotum, which, on being opened, showed that he had been suffering from an irreducible hernia, and that the efforts to reduce this had caused so much inflammatory action as to lead to sloughing of the mass of omentum of which the hernia consisted, and the formation of an abscess in the sac. Happily, the openin"s int, the peritoneal cavity was closed, and the case has progressed well.

I have, in some former papers (BRITIsH MEDICAL JockNaL, 1880, 1881 , and 1882), advanced what seem to me cogent reasons why all suitable cases of reducible hernia should be as far as possible not merely relieved, but cured-provided this can be done without undue risk to the sufferer. This is really the vital point in the consideration of this question. Are any of the operations usually performed with this object in view, sufficiently safe to warrant their frequent perform. ance? and, again, are they reliable enough to effect the desired purpose, and to render it worth while on the rart of the patient to submit to the danger and inconvenience of an uperation? An opera. tion of expediency, in order to be fully justifiable, must be reasonably safe; and if it can be shown that this is the case, the unain difficulty in the way of its more gencral adoption will be removed.

There is a general impression that a truss will effect a cure in a large proportion of instances, provided it be worn long enough-that is, for life. But we have no clear evidence of this. Instrumentmakers will tell you that, when once a truss is worn, it is usually worn for life, unless, as too often happens, it helps to bring about strangulation, and thus ends its career. Some ruptures undergo spon. taneous cure, some few may be cured by the use of a truss; but there remains a large class which are not amenable to any palliative treat. ment, and seem to demand other measures for their cure.

In boys and young men, so far as inguinal hernia is concerned, I have seen the most favourable results from $\mathrm{my}$ own operation; anci in them the results are the most satisfactory, both as regards the $p^{1} \mathrm{e}$ manence of the cure, and the safety of its performance. I have never practised it in the case of old men, though there is no reason argainst it of which I am aware. In a few instances, I have been asked to operate in gentlemen past middle age; but their high social position, and the adequate support afforded by a first-rate truss, led me to advise the continuance of its use rather than any operative measures.

Mr. Mitchell Banks, who has kindly come to give us his experience, has proved himself such an able champion of the open opera. tion by ligature, that it is superfluous for me to advocate its utility but it may be as well to draw attention to the fact that, in its earlicr days, this operation was attended by a comparatively ligh rate of mortality-a rate, indeed, sufficiently formidable to deter cautious surgeons from following it. During the last $\mathrm{few}$ years, however, this has been, to a large extent, remedied ; and the results which have been published recently are sufficiently good to justify its more general adoption.

Dr. Warren, of Boston, Massachusetts, has recorded a large number of cures by Heaton's method of injecting a decoction of oak-bark around the hernial ring. When in America recently, I founcl that several cases had been operated on in this way at New York with a fair amount of success, but the operation seems to be little adopted ganerally.

Dr. Macleod, of Calcutta, operated in twenty-eight cases by ligature, antiseptically, with six deatlis. His plan is to isolate the sac up to the internal ring, then ligature it with catgut in three places, cutting off the sac below the lowest ligature. He then stitches the inuer pillar and conjoined tendon to the outer pillar, leaving the neck of the sac as a plug in the inguinal canal. Of the whole number, seventeen were cases of reducible hernia, and among these were two deaths. But besides these, there were five cases in which suppuration and putrefaction took place. The rupture recurred in two out of eight instances where unian by first intention $t$ lok place, and the avcrage 
number of days in hospital was fifty-five. Such results as these do not say much for the safety of the method, and sufficiently show, as the Lancet remarks, that "it is a procedure not to be entered upon lightly."

I was somewhat gratified to read in the Edinburgh Medical Journal of August, 1883, some account of Dr. Neve's experience in India on this subject. The arguments he uses are so forcible, and his remarks so apposite, that I venture to reproduce some of them here.

Dr. Neve narrates nine cases in which he operated, during the year, by my method, in the Kashmir Mission Hospital, where Dr. Downes had, the year before, also operated on eight cases with success.

The patients varied in age from two months to fifty years, and in only one case was any constitutional disturbance observed; pain was seldom severe, sometimes altogether wanting. Eight of the cases are reported as cured, one recurring. This one was in a man who ran away from the hospital the day he was operated on, and only returned two days later, because he could not remove the instrument himself. Rocurrence was hardly surprising under the circumstances; that he survived the recurrence is the only wonder. Notwithstanding, the hernia was, when last seen, only about a quarter of the original size. The longest time in hospital was thirty-one days, and the shortest eight days. In no case was there any accumulation of pus, sloughing, or dangerous symptom of any kind.

Dr. Neve observed that the hardness remaining at the hernial canal "conveys an impression of great security, such as to make the spot aperated on decidedly stronger than some of the parts immediately around." He adds " of the obliteration of the sac in this operation, I entertain no doubt whatever." After a comparison between other methods and my own, Dr. Neve concludes by saying: "I am certainly not prepared to think that there can have been, or will eventually be, recurrence in more than a small proportion of the cases operated on, and hope that my small experience may contribute to show that, ir Spanton's operation for radical cure of hernia, we have a method devoid of danger of death, almost without risks of any serious results ; - a method of singular simplicity of detail and ease of application ; a method adapted for the congenital hernia of the tube, as for the large tumour and lax tissues of the old, and far more suited than more delicate, and perhaps more precise, operations for the requirements of country or colonial practice, in which it might well replace the palliative measure of a truss or bandage with which the profession has too long been satisfied."

This independent testimony is the more valuable, inasmuch as Dr. Neve is personally unknown to me, and I have had no communication, direct or indirect, with him.

To sum up, the cardinal points bearing on the question of the cure of simple hernia may be said to be necessity, safety, and efficiency. I Fave shown elsewhere, both from analogy as well as from direct evidence, that the first cannot be questioned in those cases which are not amenable to effectual treatment by means of a truss; and that we have no more right to permit a patient who consults us concerning a painful physical, and, incidentally, still more trying mental state, to continue unrelieved, than we have to refuse to remove an agonising neuroma, or excise a painful joint, on the ground that in neither case is the patient's life in jeopardy. I have also shown, and the diagrams here will exhibit, the large number of hernial subjects who die annually from strangulation, the larger proportion of whom ought to be considered as dying from a preventable cause. How common it is to see, among working men and women, an ill-fitting truss, not unfrequently upside down, rubbing on a descended rupture, and ready, when strangulation takes place, to irritate and influence the constricted bowel! When we meet with such cases, the surgeon knows only too well that his prognosis must be unfavourable, and that the unlucky truss has done its worst to vitiate the beneficial results of any operation performed for the relief of the strangulation.

Truss-dangers afford, therefore, a strong argument in favour of operative measures while a permanent cure can be safely effected. Practically, a hernial subject is an unsound one, and cannot pass a medical examination for any public service; nor will a truss avail him in the least to overcome this difficulty; but a curative operation will. One of my cases is that of a boy who was committed to an industrial school; but, on account of a rupture, according to the rules of the in. stitution, he was insdmissible. It occurred to me, therefore, to cure the boy first, and let him be admitted afterwards. This was done five years ago; and the lad has worked on the school-farm since, has become an useful, steady, working lad, instead of the alternative course of being sent to prison or among the young criminals of a reformatory. He is here for you to examine.

An instance occurred to me this year, in which a gentleman of position consulted me on account of his only son, about six months old, who had a rather large inguinal rupture. The child had worn a truss, but being a noisy, roaring infant, it was not of the slightest use. The father said to me that he would not have a child of his "not perfect," if by any means he could be made so; and expressed a strong wish to have an operation performed for the cure of the hernia. In February last I operated by my usual method, at tine same time circumcising the child for a tight phimosis, which had probably been the cause of the rupture; and I have lately heard that the result has been very satisfactory. Now, in this instance, the necessity arose from the utter uselessness of a truss, and from the full recognition on the part of the parent of his responsibility towards his young child. He has now the satisfaction of know. ing that he has done his duty, and has had his child made physically "perfect."

I ought to add that the surgeon, in whose charge the patient was, recognised his responsibility in the matter with that amount of moral courage which too many lack, by advising the performance of the operation, even in the case of a son and heir.

Of the second element-that of safety-I think I need only say that, up to the present time, no case has come to my knowledge in which death has resulted from the performance of my operation; nor have I seen or heard of a single case in which symptoms of an alarming nature have been attributable to it. No instance of general peritonitis, of erysipelas, of pyæmia or septicæmia, or any other indication of bloodpoisoning, has, so far as I am aware, been observed. The operation must have been performed at least one hundred times by different surgeons ; and there are not many operations of the same degree of gravity of which it can be said that this number has been performed, in various parts of the world, without a single fatality. It may, therefore, be looked on as a safe operation.

The ligature method can, of course, be applied to a much wider range of cases, and we shall hear from other speakers what they have accomplished in this direction. I am quite ready to admit and fully appreciate the advantages of an open dissection ; but it must be borne in mind, as I have already indicated, that the mortality hitherto from this method has been very different indeed from the subcutaneous one. As experience increases, we may expect the proportionate safety of the operation to augment also.

Lastly, as to efficiency ; some captious persons seem to think that, unless an operation can restore the abdominal walls to the same condition as they ought to have presented if the sufferer had never had a hernia at all, it cannot be called efficient. But surely this is expecting a little too much. What is usually meant by being efficient is, I take it, that a hernia, which formerly came down of its own accord, does so no longer under any ordinary provocation, and that artificial support of any description is not required. That, moreover, this condition is not only temporary, but permanent-unless, or until, a new and independent rupture may take place. Now, this efficiency is en. sured in all the cases which we call cures, and which constitute a variable proportion, which is difficult accurately to determine, of those operated upon. In some of the cases I have shown at meetings of the British Medical Association, and elsewhere, it has been almost impossible to distinguish any indication of an operation having been per. formed, without careful scrutiny. I have usually found that, where the result has remained good for twelve months, it has been permanent; and some of my cases, which you will see, were done more than five years ago. It is well never to be too hasty in assuming that an unpromising looking case is about to prove a failure. Some I have seen of this kind have turned out as satisfactory as possible in the end. A few failures need not dishearten us ; for, even in some of these, a man may be enabled to perform work for which, either with or without a truss, he was quite unfit before; and this surely is a great advantage.

I have on a former occasion described the operation I usually prac. tise. It has been objected by some that the proceeding is " occult ;" and this is, to a certain extent, true, inasmuch as it is subcutaneous. When, however, the finger is introduced under the skin, it is surprising how accurately tine parts around can be felt, and the exact position of the vessels and adjacent structures be clearly defined. For this reason, the operation is one which can be almost as exactly performed as one that is open, and we aroid some of the drawbacks incidental to the latter. Hæmorrhage is by no means trivial in some of the cutting operations ; free suppuration is tolerably frequent; and, in many, a large unsightly cicatrix is left, weakening the abdominal wall at that part. In this way, in some of these cases, I have seen the patient in a worse state than he was before anything was done. Whatever defects may be alleged against my operation, I do not remember a single instance in which, when it has failed to effect a cure, matters have been made any the worse by it. Failure in effecting a cure, is one thing; but to make the pationt worse than he was before, is quite an. 
other. Each operation has its sphere, and, while I prefer the strephotome for young patients, and for moderate-sized herniæ of the inguinal class, I am inclined to believe that, for other cases, it is best to cut down, and apply some form of ligature to the sac and abdominal rings. We must never lose sight of the fact that we rarely see two cases of hernia exactly alike; and, although we may lay down certain general rules for guidance, yet each case will have to be dealt with on its merits. What will apply to a large, lax, thin hernial opening, will certainly not answer for a small, tight, dense one; and it must necessarily rest with the surgeon himself to judge, from the nature of the condition with which he has to deal, what is best likely to succeed. Experience will teach far more on this head than arguments or statistics.

In all these cases, the risks, as well as the advantages, of an operation ought to be clearly stated to the friends of the patient, with whom the decision as to its performance should rest.

The foregoing remarks have reference chiefly to the inguinal forms of rupture, but other forms are likewise amenable to cure; and the same arguments which are applicable to the one form apply equally to the others. Among these, umbilical hernia ought specially to be mentioned. There are few conditions which entail greater discomfort, or lead to more constant danger, than a large exomphalos; but, happily, it is an infirmity which can in many instances be dealt with by operative measures. Although my instrument can be, and has been, used to remedy this condition, it seems to me the best method is that of ligature. It was first advocated by Mr. Barwell in 1861 ; and the operation he describes of opening the sac, removing any adherent or superfluous omentum or sac, ligaturing its neck, and stitching the edges of the umbilical opening, is the same as that now usually practised. Mr. Mitchell Banks and Mr. Lawson Tait, as well as my colleague, Mr. Folker, have had considerable experience of this operation, and we shall, no doubt, hear their views upon it. The last patient on whom I operated was enormously fat, as most of them are, with a very large hernia, more or less adherent to the sac. I removed a large portion of omentum, with the whole of the sac, which was securely tied with silk, and the edges of the opening, after being pared, stitched together. The result was quite satisfactory.

In femoral and ventral herniæ, too, the ligature is most valuable, and has now been employed in a sufficient number of cases to warrant its more general adoption.

Having said so much in favour of operative measures, it must not be inferred that they are advocated for universal or indiscriminate adoption. Nothing of the kind. Of course, a patient suffering from any serious chronic disease-especially tubercular-from habitual cough, or other ailment, which would contraindicate any ordinary surgical procedure, would be equally unfitted for this. The chief sources of danger are to be found in some of the forms of inflammatory action-peritonitis, diffuse cellulitis, orchitis, hæmorrhage, and septicæmia.

In some cases, sharp orchitis has taken place, with considerable œdema of the scrotum; but this, within certain limits, is not to be deprecated, as it shows that the spermatic cord has been tightly compressed by the closure of the canal ; and no ultimate harm arises from it. I have met with localised cellulitis, in a few instances, which resulted in free suppuration along the line of the instrument. In one, this was caused by the restlessness of the patient, with a strumous habit. No further harm resulted than delayed convalescence, though, in one instance, the free suppuration prevented adhesive union, and caused the operation to be unsuccessful. Peritonitis ought never to happen if the neck of the sac be securely closed, so that the peritoneal cavity is at once shut off; and, to guard against septicæmia, every possible surgical precaution ought, of course, to be rigidly taken.

These are the chief dangers; but there are some inconveniences ob. served sometimes which deserve brief mention. One is the rather frequent occurrence of retention of urine. It usually lasts only a day or two, and is, of course, at once remedied by the use of the catheter. Pain is sometimes rather considerable; usually it is very trivial, but occasionally requires the free use of sedatives. I am disposed to attribute it to the inclusion of the ilio-inguinal nerve, for, as soon as the strephotome is removed, the pain usually ceases. In very young children, the difficulty of keeping on the dressings has led me to adopt the alternative of not attempting it, but simply to keep the wound constantly moistened with eucalyptus, or other antiseptic oil, and leave it open. Cases so treated recovered quite as well as others. One instance only I remember where the bowel descended while the instrument was in position. In this case, the child ras a cross loud-crying one, and the hold on the internal pillar gave way. No harm was done; the instrument was at once removed, and a second operation subsequently performed, which resulted in success. In another case, where the operation was successful in curing the oblique inguinal rupture, so much thinning of the abdominal wall took place, over the situation of the internal ring, that a direct inguinal hernia resulted. This appeared to be an illustration of one of the reasons advanced by some authors against all operative measures-namely, the inability of certain abdomens to find room for their contents, so that they must protrude somewhere. But even in this case, the small direct hernia was easily amenable to control by a light truss, whereas what it replaced was quite unmanageable.

These constitute, I think, the principal drawbacks to the operation; and it will be acknowledged that they are trivial, compared to many which might be named, associated with other and less important surgical proceedings; but I have been anxious not to exaggerate the advantages, on the one hand, nor to extenuate the dangers, on the other - even at the risk of being unnecessarily prolix.

\section{ON THE RADICAL CURE OF HERNIA. Read before the Staffordshire Branch.}

By VINCENT JACKSON, F.R.C.S.Ed., M.R.C.S.Eng., Senior Surgeon to the Wolverhampton and Staffordshire General Hospital.

IT is now twenty-five years since Wutzer recommended his well known treatment for the cure of hernia ; a treatment which, although a very fair and impartial trial was given to it, signally failed to permanently accomplish what it professed to be enabled to do.

Professor Wood materially revived the attention of surgeons to the operative treatment of these cases. This operation was, and is, practised by many. Mr. Spanton simplified Wood's operation, and a large measure of success has been obtained by its employment. But the question arises, can the operation of Wood or of Spanton truthfully be called a radical cure? Have not both of these operations failed in some cases to effect a temporary cure; and, in others, has not a return of the hernia when a truss has not been worn, even is promising cases, been a cause of disappointment alike to patient and to surgeon? To me it seems a misnomer to call an operation radical, which requires the wearing of a support to prevent its becoming ineffectual ; and while I admit my admiration of the ingenuity displayed by the authors of the two operations alluded to, yet I am bound to say that, in my opinion, the only operative procedure which can justly be spoken of as radical is, when the sac is either dissected away or pushed within the abdomen, and the pillars of the external ring, where possible, completely and permanently united.

If the handiwork of the operator upon the lines just indicated be rewarded by a successful recovery, I can hardly conceive the possibility of a relapse, for the closed pillars seem to me to be as much a barrier to a re-descent as the pad of any truss. How are the pillars to be maintained closed ? Not by the use of silk or gut sutures, but by the employment of silver wire.

Mr. Mitchell Banks has spoken strongly upon the importance of metallic sutures, and he says that he has found a single tie sufficient to prevent separation of the two ends. I have, however, generally finished off with a twist or two.

But while I have thus expressed myself, truth, sincerity, and experience compel me to state that, in my opinion, a place will always be found for Spanton's operation. There are many cases of inguinal hernia in which it is not only applicable, but perhaps preferable to the other methods.

I will now narrate the history and notes of my last operative case for the cure of hernia.

H. C., aged 18 months, was admitted into the Wolverhampton and Staffordshire General Hospital, August 19th, 1884. The mother reported that the baby was still unweaned, and had suffered almost from birth from a right inguinal hernia; and although a truss had been applied and worn more or less, yet the hernia continually came down, and at last its size became so great that a truss was powerless to prevent its descent. This unpleasant condition was so troublesome, and at times occasioned so much pain, that the parents requested the performance of some operation to palliate or cure the defect. The child was healthy, and well nourished. The hernia was with ease replaced; the rings, easily admitting the middle finger, were large, and almost in direct apposition.

On the left side, there was no evidence of the presence of a hernia or of any weakness of the abdominal walls in the usual situation of a hernial protrasion; the external ring was thoroughly competent. To test the accuracy of the mother's statement, the truss-maker to the hospital was requested to fit a truss to the patient, but with a negative result; for, upon standing or crying, down came the bowel.

The child having been weaned, and being in every way in a suit- 